\title{
Research on Improving College Students' Practical Ability based on Virtual Business Society Environment
}

\author{
Cheng Wei, Yang Shuguo* \\ School of economics and management, Heilongjiang Bayi Agricultural University, Daqing, \\ Heilongjiang province, China \\ *corresponding author: 369783225@qq.com
}

Keywords: Employability, Entrepreneurship Education, Virtual Business Society Environment

Abstract: With the increasing popularity of higher education in recent years, the employment situation is increasingly severe, and the employment channels are diversified. Under the influence of today's severe employment situation, entrepreneurship has become a major theme for college students to choose their future after graduation. Starting a business after graduation has become a new employment trend. However, the road to entrepreneurship is extremely difficult. Entrepreneurship education has become an important part of university education. However, the existing education system in China lacks the cultivation of students' Entrepreneurship and innovation spirit and skills. According to the current situation of employment education of college students in China, the research on virtual simulation project of enterprises is helpful to promote the development of entrepreneurship education in China. First of all, we should organize and train excellent entrepreneurship education teachers and strengthen the construction of entrepreneurship education teachers. Secondly, we should establish a suitable education curriculum system to systematically improve the training of students' employability. Finally, we choose to apply the advanced auxiliary system of entrepreneurship education to improve the practical teaching effect of entrepreneurship education.

\section{Introduction}

The current education system in China lacks the cultivation of students' Entrepreneurship and innovation spirit and skills, and the popularity of entrepreneurship education in universities is low.[1].The innovation and entrepreneurship education of college students is the requirement of the development of the times, the need of national development, the powerful power of economic development and transformation, and the important content of higher education teaching reform[2].Virtual Business Society Environment(VBSE) is a multi-disciplinary comprehensive practical teaching platform for colleges and universities. Through the systematic simulation of 
typical units, departments and posts in the real business social environment, students can experience the practical training before work, recognize and be familiar with the work content and characteristics of different organizations and professional posts in the modern business society, and cultivate the comprehensive executive ability required by students to engage in business management. In business management process, VBSE make college student have overall awareness and comprehensive professional quality company with comprehensive decision-making ability and innovation ability. The basic objectives of comprehensive practical training are to cultivate practical personnel with high potential and overall view. The goal is to design and realize through the concept of real work.

VBSE virtual business society provides guidance system and relevant teaching environment for enterprise operation simulation practice, which enables students to learn basic business processing based on positions, experience business decision-making based on positions, understand the relationship between position performance and organizational performance, and truly feel the three flows of enterprises (Logistics, information flow, capital flow); fully understand the business management activities and main business processes of the enterprise; experience the business relations between the functional departments of the enterprise and the relevant peripheral economic organizations and management departments such as the cooperation between the government and enterprises. Through repeated practice in teaching, students can form behavior, intelligence activity and professional behavior ability that meet the requirements of real economic activities. Achieve the requirements of fully understanding the enterprise experience position.

Enterprise is the basic unit of social economy, and its development is restricted by its own conditions and external environment. The survival of enterprises and the competition among enterprises should not only abide by the national laws and administrative regulations, but also abide by various agreements in the industry. Before the start of enterprise simulation competition, the staff of each position must understand and be familiar with these rules, so as to achieve legal operation and survive and develop in the competition.

\section{Current situation of VBSE training}

After year-on-year enrollment expansion of universities, the number of new college students in 2019 has exceeded more than 8 million, nearly 10 million. In fact, according to the population base of China, the number of college students in China is not large at present, so there are many places where college students are needed. The employment rate of graduates in 2018 is $91.5 \%$. Among them, the employment rate of undergraduate graduates $(91.0 \%)$ continued to slow down, 1.6 percentage points lower than that of 2014 (92.6\%); the employment rate of Vocational and technical graduates was $92.0 \%, 0.5$ percentage points higher than that of 2014 (91.5\%). The employment rate of recent two graduates is higher than that of the same undergraduate [3]. Although undergraduates have relatively solid professional theoretical knowledge, but in front of the employment rate, it is obviously not enough to only master professional theoretical knowledge. The purpose of using VBSE platform to develop the innovation and entrepreneurship ability of undergraduate students is to build the application-oriented talent training mode. Through the organic combination of "theoretical knowledge", "professional quality" and "hands-on skills", from the work content, management process and business documents of the real post, the operation simulation is connected with the real work, and the simulation operation and business operation are carried out.We will integrate the concept of innovation and entrepreneurship education into the undergraduate talent training program, integrate innovation and entrepreneurship education into professional courses and professional practice teaching, strengthen the integration of innovation and entrepreneurship education and professional education, so as to build a new system of interdisciplinary, research and 
application integration, teaching and innovation and entrepreneurship integration, and cultivate high-level talents with strong innovation spirit and entrepreneurship potential.[4] It is suitable to match the business rules of teaching objectives, cultivate practical post managers with high potential and overall view, so as to improve the training of students' colleges.

Taking Heilongjiang Bayi Agricultural University as an example, since 2012, VBSE platform has been used to carry out practical training in the University domestic. In the past eight years, more than 3000 students have been trained in the school of economics and management, and 3200 class hours have been accumulated for teachers. Because of the good effect of the practical training in the school, most of the students who take part in the VBSE experimental course are satisfied with this kind of training method. At present, the experiment has been set up as an experimental course separately. Since 2017, it has been included in the skill training program of the school of economics and management, striving to promote the experimental course as an elective course of the whole school and promote the course within the scope of the whole school. In the next five years, it is planned to preliminarily reach cooperation with surrounding enterprises in Daqing city to conduct one month's induction training for new employees.

\section{Main advantages of VBSE training}

\subsection{Reduce the time cost of finding internship units}

Most colleges and universities organize students to participate in internship training both inside and outside the University in the third year of students' enrollment. Taking the school of economics and management of Heilongjiang Bayi Agricultural University as an example, the departments of agricultural and forestry economics and management, international economy and trade, logistics, marketing and human resources need to spend a lot of human and material resources to seek professional related enterprises to provide training bases for students inside and outside the university every year before VBSE is applied. Sometimes, because departments can't find a suitable internship unit, the internship time will be delayed. There are too many uncertain factors to contact the internship enterprise. Due to the limitation of internship time, the position offered by internship enterprises, and the geographical location of internship enterprises, the effect of internship is not as good as expected. It is often just to do some simple work just like copying documents and sorting out the office sanitation, which is not related to the specialty.

\subsection{Improve the effect of ability development during practice}

VBSE virtual business society provides guidance system and relevant teaching environment for enterprise operation simulation practice, which enables students to learn basic business processing based on specific positions, experience business decision-making based on positions, understand the relationship between position performance and organizational performance, and truly feel the three flows of enterprises (Logistics, information flow, capital flow), fully understand the business management activities and main business processes of the enterprise; experience the business relations between the functional departments of the enterprise and the relevant peripheral economic organizations and management departments such as the cooperation between the government and enterprises. Through repeated practice in teaching, students can form behavior, intelligence activity and professional behavior ability that meet the requirements of real economic activities. To achieve the requirements need students fully understanding the enterprise experience position. Through the role training of different professions, students can exercise the comprehensive executive ability, comprehensive decision-making ability and innovation and entrepreneurship ability in economic 
management.

\subsection{Experience the whole process of enterprise operation}

The comprehensive cross specialty training is a comprehensive practical teaching course for the major of economics and management in colleges and universities. Through the extraction of the typical characteristics of different forms of organizations, the course creates a virtual business social environment, which enables trainees to simulate the business simulation with the real work in the virtual market environment, business environment, government environment and public service environment according to the real job content, management process, business documents and the business rules suitable for the teaching objectives real operation and business operation, which can carry out macro and micro management, multi person collaborative simulation operation. So as to train students' comprehensive executive ability, comprehensive decision-making ability and innovation and entrepreneurship ability, and cultivate students' overall awareness and comprehensive professional quality.

\section{Suggestions}

\subsection{Attach importance to investment in auxiliary infrastructure.}

Infrastructure projects have always been an important part in China's in higher Education. In the past two decades, policies have been in great help from the central government to the local governments, which can be said to be of great significance invest in higher Education. Recently, affected by the overall entrepreneurship education environment and financial support policies, infrastructure investment and financing are facing an unprecedented new situation in VBSE. VBSE uses Internet technology and related computer hardware to operate under certain conditions. The purchase of hardware facilities is only the basic premise for VBSE test. However, the training of the corresponding teachers and the purchase of some VR auxiliary facilities may better improve the effect of VBSE experiment.

\subsection{VBSE open to the whole society}

We should stick to the importance of science popularization and technological innovation. Science popularization and innovation are not only equally important, but also directly affect or even determine the degree of innovation. Because science popularization is the premise and foundation of scientific and technological innovation, without science popularization, there can be no lasting scientific and technological innovation. Among many popular science models (activities), popular science in Colleges and universities, especially in laboratories, has become one of the key platforms for the dissemination of scientific methods, spirit, ideas and knowledge by virtue of its advanced technicians and sophisticated equipment. However, for Heilongjiang Bayi Agricultural Reclamation University, the scientific popularization effect of university laboratories, including those undertaking high-tech R \& D tasks, is not strong, "most of the management methods of university laboratories are relatively closed" can not effectively meet the needs of the public for the scientific popularization of university laboratories, and the scientific popularization effect of laboratories has not been fully played.

\subsection{Actively integrate new technologies in other fields}

In the mobile Internet environment, the development of new technologies such as big data, Internet 
of things, artificial intelligence and block chain is changing with every passing day, and showing a trend of increasingly integrated development. Many well-known experts in the field of scientific research and innovation, have been paying attention to not only the development of new technology, but also the improvement of social and economic benefits brought by the development of new technology, as well as the practical impact on management reform.

To make outstanding contributions to the construction of courses for improving students' entrepreneurship ability. Entrepreneurship education needs the cooperation of the whole society to entrepreneurship education. The cultivation of entrepreneurship ability is not only the cultivation of entrepreneurship awareness and theory in Colleges and universities, but also the support of the government to provide policies and services for College Students' entrepreneurship practice activities, as well as the assistance of social and family environment countermeasure.

\section{Acknowledgments}

This research is financially supported by the: The first group of virtual simulation experiment teaching projects in Heilongjiang Province: VBSE cross professional comprehensive experiment-procurement business training (Heilongjiang Higher Education official document [2018] No.373).

\section{References}

[1] Mu Zhirong. Discussion on the mode of entrepreneurship education for college students in China. Higher education research, 2006, (11). pp: 79-84

[2] Xu Detao. Research on innovation and entrepreneurship education of college students. Shandong University. 2013

[3] http://www.199it.com/archives/930684.html Employment report of Chinese college students in 2019

[4] Liu Yan, Yan Guodong, Meng Wei. Deep integration of innovation and entrepreneurship education and professional education. University education in China. November 2014, (26). pp: 35-37. 